\title{
Pattern and Distribution of Malaria Disease in Wulu- A Typical County in South Sudan
}

\author{
Article by Gabriel Omoniyi Ayeni ${ }^{1}$, Okwuoma C. Abanobi ${ }^{2}$, Daniel O. Ebenezer ${ }^{3}$, Olagbegi M. \\ Oladapo $^{4}$, Oyewale M. Morakinyo ${ }^{5}$ \\ ${ }^{1}$ Public Health Dept, Texila American University, Guyana, South America \\ ${ }^{2}$ Federal University of Technology, Owerri, Nigeria \\ ${ }^{3}$ Texila American University, Guyana, South America \\ ${ }^{4}$ Rhodes University, Grahamstown, South Africa \\ ${ }^{5}$ University of Ibadan, Ibadan, Nigeria \\ E-mail: ayenco_2@yahoo.com
}

\begin{abstract}
South Sudan was reported as having one of the highest malaria burdens in sub-Saharan Africa. A better understanding of the pattern and distribution of the infection is considered to have implication on prevention and control. The objective of this study was to investigate the pattern and distribution of reported Malaria infection in Wulu, South Sudan

Secondary data on malaria cases managed between January 2014 and December 2016 across all the eleven health districts of the county were obtained from the Health Management Information System and the District Health Information Software. Descriptive statistics were used to analyze the extracted data.

The finding showed similar trend in the pattern and distribution of Malaria disease across the health districts between 2014 and 2016. Also the incidence rates for the overall population were 29.5\%, 23.7\% and 36.7\% for 2014, 2015 and 2016 respectively. However a much higher incident rate was recorded among the under-5 year population for the same period $(76.5 \%, 47.1 \%$, and $64.5 \%)$. Malaria cases among under-5 years of age in the area account for 52-59\% of Outpatient department consultations between 2014 and 2016. Also the finding showed sharp rise in the number of cases reported for 2016 although the same yearly trend was maintained across the year and districts.

The finding showed similar trend in pattern and distribution of Malaria infection over the period of 2014 to 2016 and across the health districts; it did not however suggest a reduction in the trend of occurrence. More attention should be given to the under-5 year population.
\end{abstract}

Keywords: Malaria, Pattern and distribution, Outpatient department, Under-5 years, Wulu.

\section{Introduction}

According to the estimates from World Health Organization (WHO, 2015), between 2000 and 2015, malaria incidence rates fell by $37 \%$ globally and malaria mortality rates fell by $60 \%$ (65\% in under five children) globally. Since 2000, the malaria mortality rate declined by $72 \%$ in the Region of the Americas, by 65\% in the Western Pacific Region, by 64\% in the Eastern Mediterranean Region, by 66\% in Africa Regions and by $49 \%$ in the South-East Asia Region. About 214 million new cases of malaria worldwide in 2015 was reported with African Region accounting for most global cases of malaria (88\%), followed by the South-East Asia Region (10\%) and the Eastern Mediterranean Region (2\%) while the European Region reported zero indigenous cases of malaria for the first time (WHO,2015). Despite this reported declining trend in the incidence of Malaria diseases, could similar pattern or trend be reported in geographical areas of south Sudan?

Malaria is the leading cause of morbidity and mortality in South Sudan (RoSS,2009), accounting for $20 \%$ to $40 \%$ morbidity with over $20 \%$ of deaths reported in health facilities and $30 \%$ of all hospital 
Texila International Journal of Public Health

Volume 5, Issue 3, Sep 2017

admissions (Chanda et al, 2013). Parasite prevalence ranges across the states and is higher in rural areas than in urban areas (Chanda et al, 2013). The overall incidence of malaria according to Abdalla et al (2007) was 282 per 1,000 population and was higher in males than in females but the mortality rate of malaria was the same in males and females. Mortality was highest in children less than five years old and declined in older age groups (Abdalla et al, 2007). World Malaria report (WMR) put the incidence at about 200 per 1000 population as at 2015 (WHO, 2015).

The country was reported having one of the highest malaria burdens in sub-Saharan Africa (WMR, 2015). Approximately $95 \%$ of South Sudan was reported endemic of malaria, with high transmission in the country throughout the year. Malaria accounts for $20-40 \%$ of all health facility visits, $30 \%$ of all hospital admissions, and is a leading cause of death. Malaria is the leading cause of illness and death in children under five years in Southern Sudan (ROSS 2009). It also contributes to anaemia in children and is a common cause of absenteeism from school. To effectively address this problem, it is very pertinent to first understand the pattern and distribution of Malaria disease among the population in a typical geographical area of the country. An answer to this would guide health planners and managers to deploying a more effective approach and/or methods to combating the scourge.

This study, therefore, aimed to investigate the pattern and distribution of malaria disease in the geographical area and review its implication for further studies and effective management plan for the disease. It was meant to provide needed information for health policy makers, health managers and health researchers on the trends and a peep into the possible impact of past and present health intervention.

\section{Methods}

This is a descriptive study which examined the pattern and distribution of Malaria diseases in Wulu County, a typical County in South Sudan. Wulu is an agrarian area with about 60,000 populations. It is one of the four greater counties of Western Lakes State, South Sudan. It lies on latitude N-06 30' 31.66", and longitude E $029^{\circ} 37^{\prime} 38.09^{\prime \prime}$. All relevant data for the past three years (2014-2016) were examined to be able to present a picture or representation of Malaria disease within that period.

The design of this study was a descriptive retrospective study. This was used to investigate the past data on malaria diseases from all the eleven health districts/facilities. Data in the District Health Information Software -DHIS and the facilities Health Management Information System HMIS reporting tools were retrieved.

Secondary data were retrieved and analyzed to provide an insight into what, where and when of Malaria disease between 2014 and 2016 in the area. This was to provide the foundation for answering the 'why' and 'which' methods/approach or 'how' best the diseases could be better confronted and significantly reduce its burden.

The data collected was analyzed using SPSS computer software version 17 (SPSS, Inc., Chicago, IL). Descriptive statistics of mean, ratio or proportion, frequency, rates with graphs and charts was carried out. The total OPD utilization ratio was calculated by dividing the total number of OPD consultations in a year by the total population for the same year. The number of reported malaria was divided by the number of OPD consultation to derive the percentage of malaria out of the OPD consultations.

\section{Result}

Malaria data from the eleven health facilities in the county were analyzed. The charts and tables below give the representation of the finding of the study. It showed the pattern and distribution of malaria cases. The result has to a large extent provide answers to the 'person', 'place' and time epidemiologic concept as regard Malaria among the population.

The result as shown in figure 1, 2, 3 showed a consistent pattern of Malaria Disease over the past three years of 2014, 2015 and 2016 looking at the whole population and also across geographical areas. There was a finding from this study of a sharp rise in number of reported cases in the third year under review, although the pattern and distribution of its occurrence appeared to have been maintained during the period. 
Texila International Journal of Public Health

Volume 5, Issue 3, Sep 2017

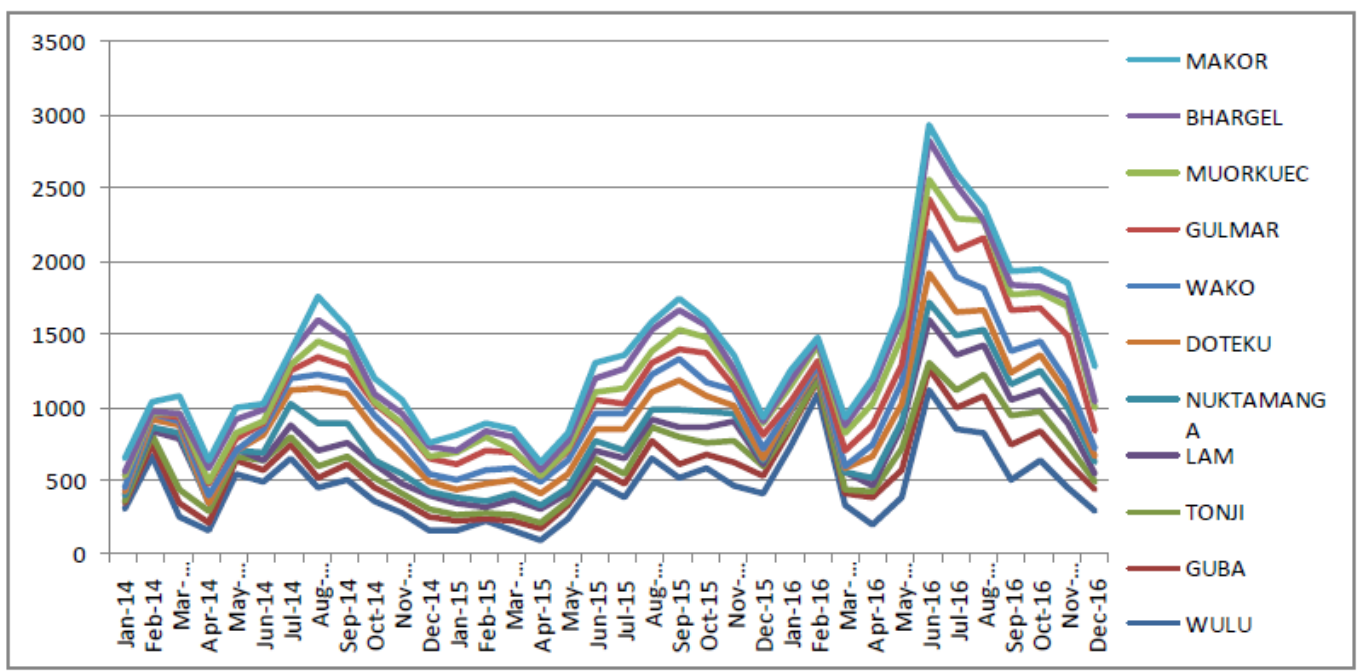

Figure1. Wulu County health facilities reported malaria incidence trend (time occurrence series) - January 2014-

December 2016

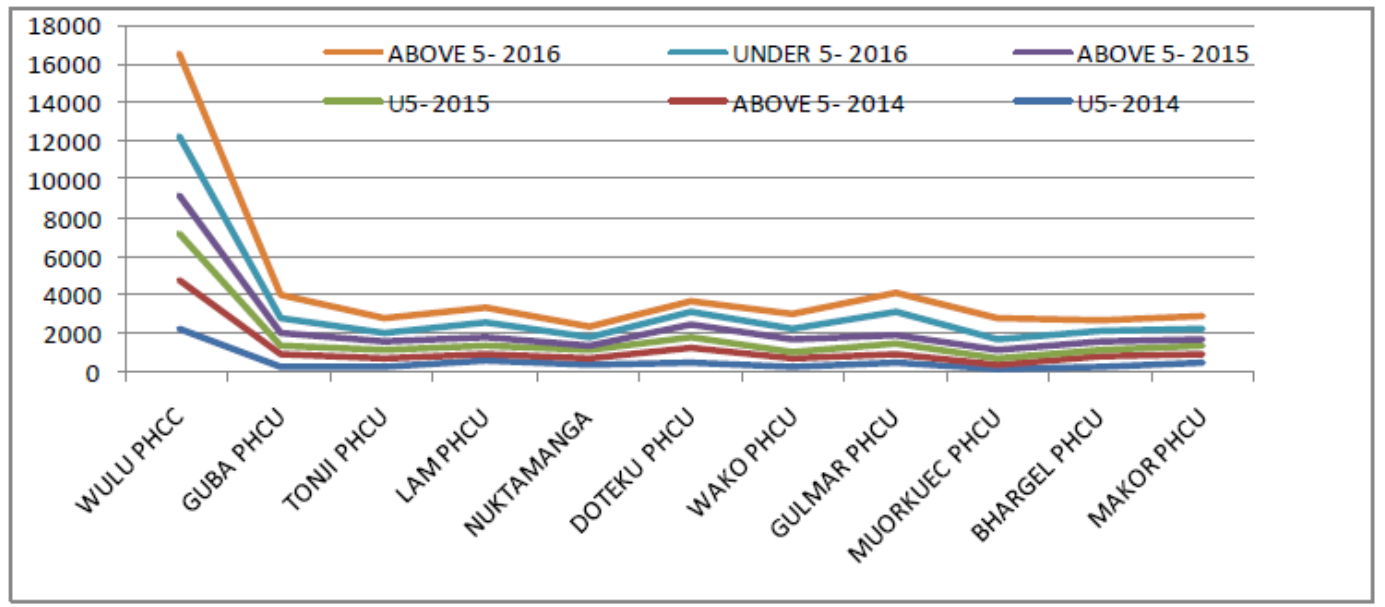

Figure 2. Line chart showing malaria cases treated at health districts/facilities between January 2014 and December 2016 
Texila International Journal of Public Health

Volume 5, Issue 3, Sep 2017

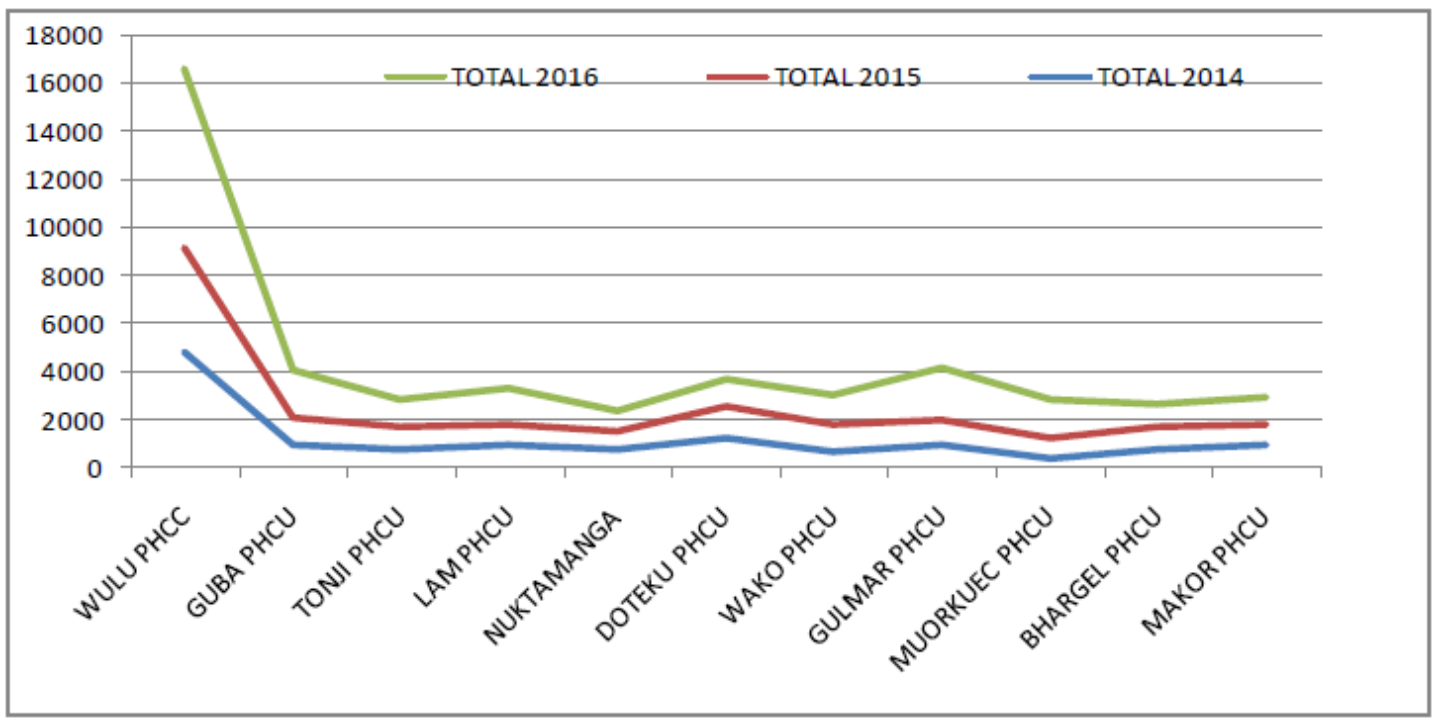

Figure 3. Line chart showing total reported malaria cases at health districts/facilities between January 2014 and December 2016

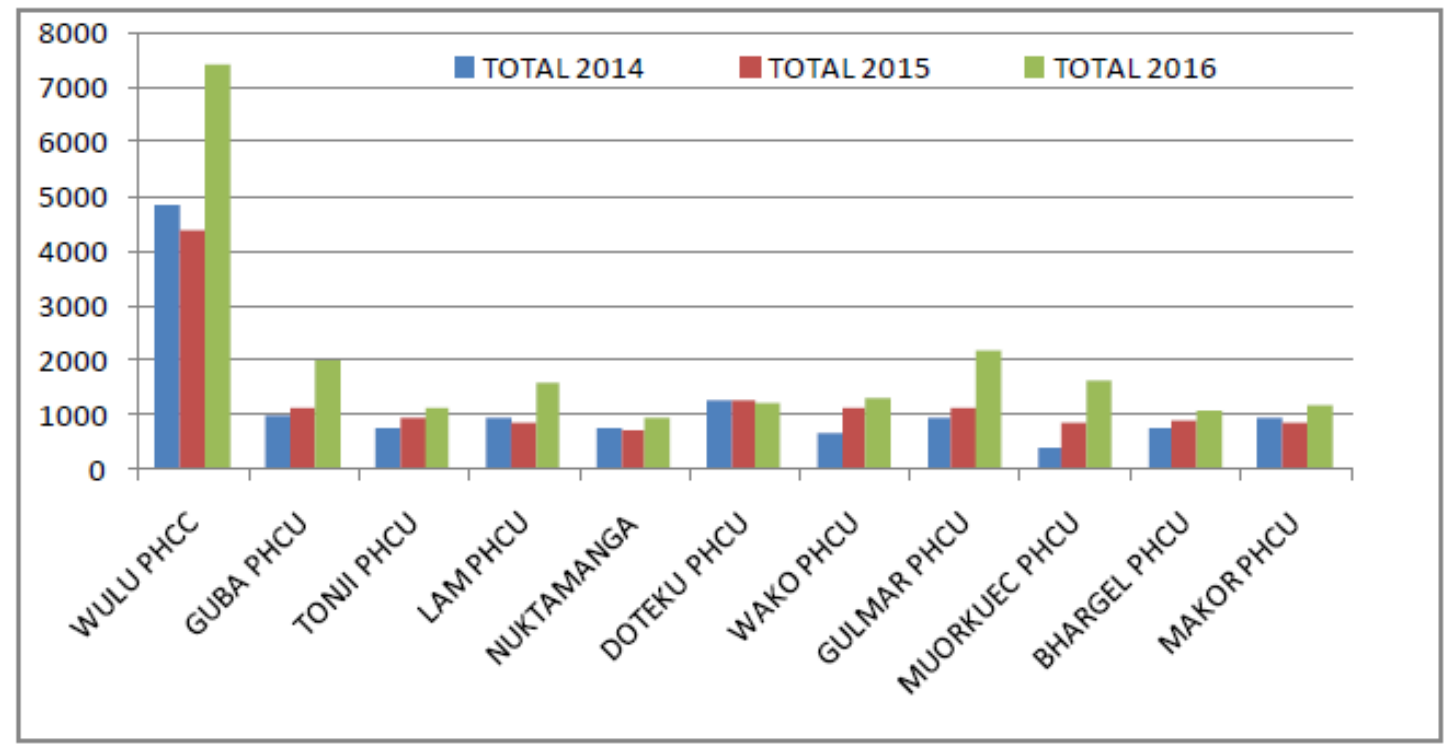

Figure 4. Bar chart showing reported malaria cases at health districts/facilities between January 2014 and December 2016

The study finding as shown in Table 1 and 2 revealed Malaria to stake a large proportion of Total OutPatient Department (OPD) Consultations. The result of this study also showed lower proportion of reported cases of severe Malaria despite the relatively high number of Malaria cases reported to have been treated. Presented in Table 3 are the incidence rates of Reported Malaria and Severe Malaria Cases. 
Table 1. Analysis of Reported Malaria cases to Total OPD Consultation

\begin{tabular}{|l|l|l|l|}
\hline Variables & $\mathbf{2 0 1 4}$ & $\mathbf{2 0 1 5}$ & $\mathbf{2 0 1 6}$ \\
\hline $\begin{array}{l}\text { Reported Malaria } \\
\text { cases }\end{array}$ & 12,814 & 13,256 & 21,451 \\
\hline $\begin{array}{l}\text { Total OPD } \\
\text { Consultation }\end{array}$ & 25,254 & 31,573 & 39,105 \\
\hline $\begin{array}{l}\text { Reported Malaria } \\
\text { cases to Total OPD } \\
\text { Consultation (\%) }\end{array}$ & 50.7 & 42.0 & 54.9 \\
\hline
\end{tabular}

Table 2. Analysis of Total OPD Utilization Rate

\begin{tabular}{|l|l|l|l|}
\hline Variables & $\mathbf{2 0 1 4}$ & $\mathbf{2 0 1 5}$ & $\mathbf{2 0 1 6}$ \\
\hline $\begin{array}{l}\text { Total OPD } \\
\text { Consultation }\end{array}$ & 25,254 & 31,573 & 39,105 \\
\hline Total Population & 43,394 & 55,885 & 58,435 \\
\hline $\begin{array}{l}\text { Total OPD Utilization } \\
\text { Rate }\end{array}$ & 0.58 & 0.57 & 0.67 \\
\hline
\end{tabular}

Table 3. Analysis of Incidence Rates of Reported Malaria, Severe Malaria Cases and rate of severe cases among the total population

\begin{tabular}{|l|l|l|l|}
\hline Variables & $\mathbf{2 0 1 4}$ & $\mathbf{2 0 1 5}$ & $\mathbf{2 0 1 6}$ \\
\hline Reported Malaria cases & 12,814 & 13,256 & 21,451 \\
\hline $\begin{array}{l}\text { Reported Severe Malaria } \\
\text { Cases }\end{array}$ & 984 & 1240 & 1,940 \\
\hline Total Population & 43,394 & 55,885 & 58,435 \\
\hline $\begin{array}{l}\text { Incidence rate (\%) of } \\
\text { reported Malaria cases }\end{array}$ & 29.5 & 23.7 & 36.7 \\
\hline $\begin{array}{l}\text { Incidence (per '000 } \\
\text { population) of reported } \\
\text { Severe Malaria cases }\end{array}$ & 22.7 & 22.2 & 33.2 \\
\hline $\begin{array}{l}\text { Rate (\%) of Severe Malaria } \\
\text { cases among total malaria } \\
\text { cases reported }\end{array}$ & 7.7 & 9.4 & 9.0 \\
\hline
\end{tabular}

Presented in Table 4, 5 and 6 are the data on the under-five year old population in the area. The finding revealed malaria consultations as constituting big chunk of OPD consultations (52-59\%). This is very high. The incidence rates of Reported Malaria and Severe Malaria Cases were much higher in under-five year old population when compared to the incidence from the overall population data analysis. 
Texila International Journal of Public Health

Volume 5, Issue 3, Sep 2017

Table 4: Analysis of Reported Under5 years (U5) Malaria cases to U5 OPD Consultation

\begin{tabular}{|l|l|l|l|}
\hline Variables & $\mathbf{2 0 1 4}$ & $\mathbf{2 0 1 5}$ & $\mathbf{2 0 1 6}$ \\
\hline $\begin{array}{l}\text { Reported U5 Malaria } \\
\text { cases }\end{array}$ & 5508 & 6,516 & 9,123 \\
\hline U5 OPD Consultation & 9,346 & 12,516 & 15,449 \\
\hline $\begin{array}{l}\text { Reported U5 Malaria } \\
\text { cases to U5 OPD } \\
\text { Consultation (\%) }\end{array}$ & 58.9 & 52.1 & 59.1 \\
\hline
\end{tabular}

Table 5. Analysis of Reported Under5 years (U5) OPD Utilization Rate

\begin{tabular}{|l|l|l|l|}
\hline Variables & $\mathbf{2 0 1 4}$ & $\mathbf{2 0 1 5}$ & $\mathbf{2 0 1 6}$ \\
\hline U5 OPD Consultation & 9,346 & 12,516 & 15,449 \\
\hline U5 Population & 7,203 & 13,830 & 14,156 \\
\hline $\begin{array}{l}\text { U5 OPD Utilization } \\
\text { Ratio }\end{array}$ & 1.30 & 0.91 & 1.09 \\
\hline
\end{tabular}

The pattern and distribution of Malaria disease showed similar trend across the health districts between 2014 and 2016; the seasonal fluctuations of incidence of malaria disease maintained similar pattern across the years and across the health districts

Also the incidence rates for the overall population were $29.5 \%, 23.7 \%$ and $36.7 \%$ for 2014,2015 and 2016 respectively. However a much higher incident rate was recorded among the under-5 year population for the same period $(76.5 \%, 47.1 \%$, and $64.5 \%)$. Similar higher occurrence is noted for severe malaria cases among the under-5 population.

Malaria cases among under-5 years of age in the area account for 52-59\% of Outpatient department consultations between 2014 and 2016.

Also the finding showed significant rise in the number of cases reported for 2016 although the same yearly trend was maintained across the districts.

Table 6. Analysis of Incidence Rates of Reported Malaria, Severe Malaria Cases and rate of severe cases among the under-5 year population

\begin{tabular}{|l|l|l|l|}
\hline Variables & $\mathbf{2 0 1 4}$ & $\mathbf{2 0 1 5}$ & $\mathbf{2 0 1 6}$ \\
\hline $\begin{array}{l}\text { Reported U5 Malaria } \\
\text { cases }\end{array}$ & 5,508 & 6,516 & 9,123 \\
\hline $\begin{array}{l}\text { Reported U5 Severe } \\
\text { Malaria cases }\end{array}$ & 456 & 580 & 843 \\
\hline U5 Population & 7,203 & 13,830 & 14,156 \\
\hline $\begin{array}{l}\text { Incidence rate (\%) of } \\
\text { Reported U5 Malaria } \\
\text { cases }\end{array}$ & 76.5 & 47.1 & 64.5 \\
\hline $\begin{array}{l}\text { Incidence (per '000 } \\
\text { population) of reported } \\
\text { U5 Severe Malaria cases }\end{array}$ & 63.3 & 41.9 & 59.8 \\
\hline $\begin{array}{l}\text { Rate (\%) of Severe } \\
\text { Malaria cases among total } \\
\text { malaria cases reported }\end{array}$ & 8.3 & 8.9 & 9.2 \\
\hline
\end{tabular}




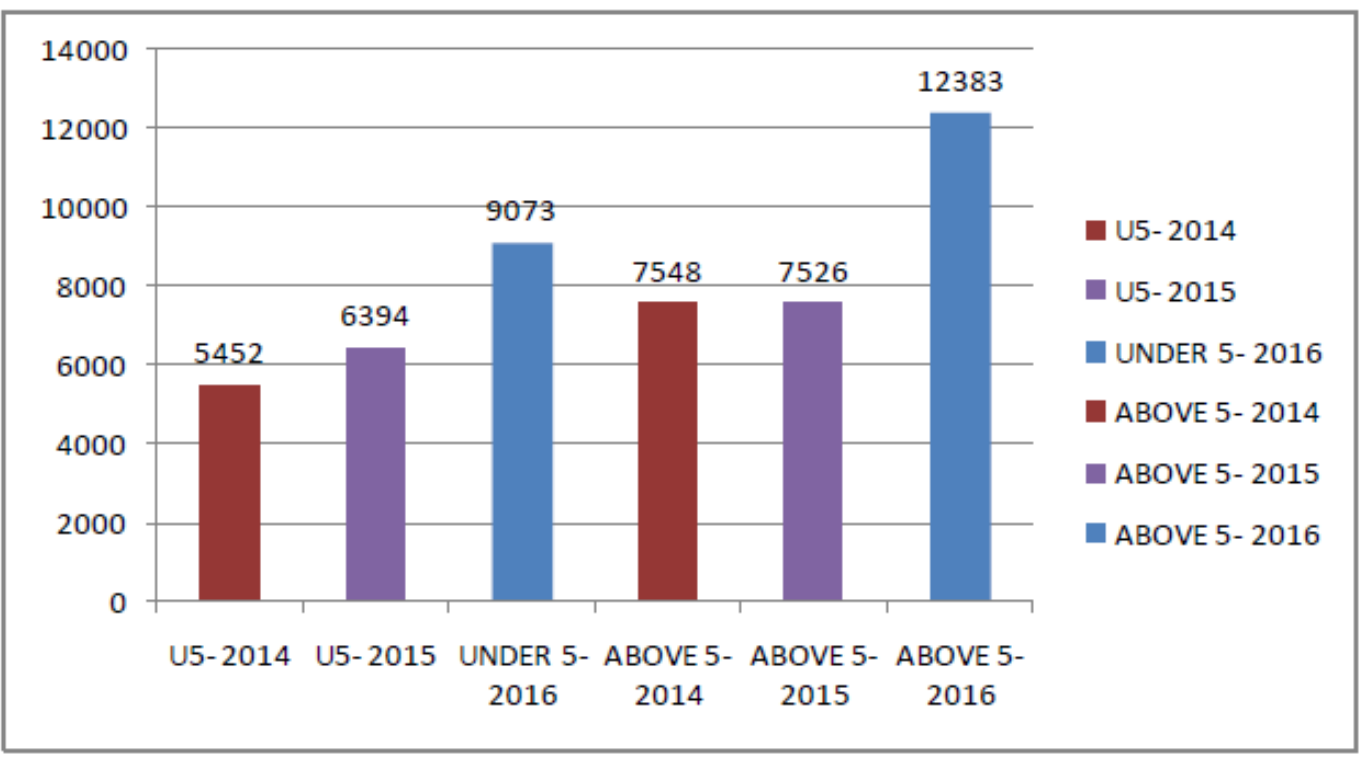

Figure 5. Bar chart showing malaria cases treated at health districts/facilities between 2014 and 2016 segregated into under-5 and above 5 years age groups

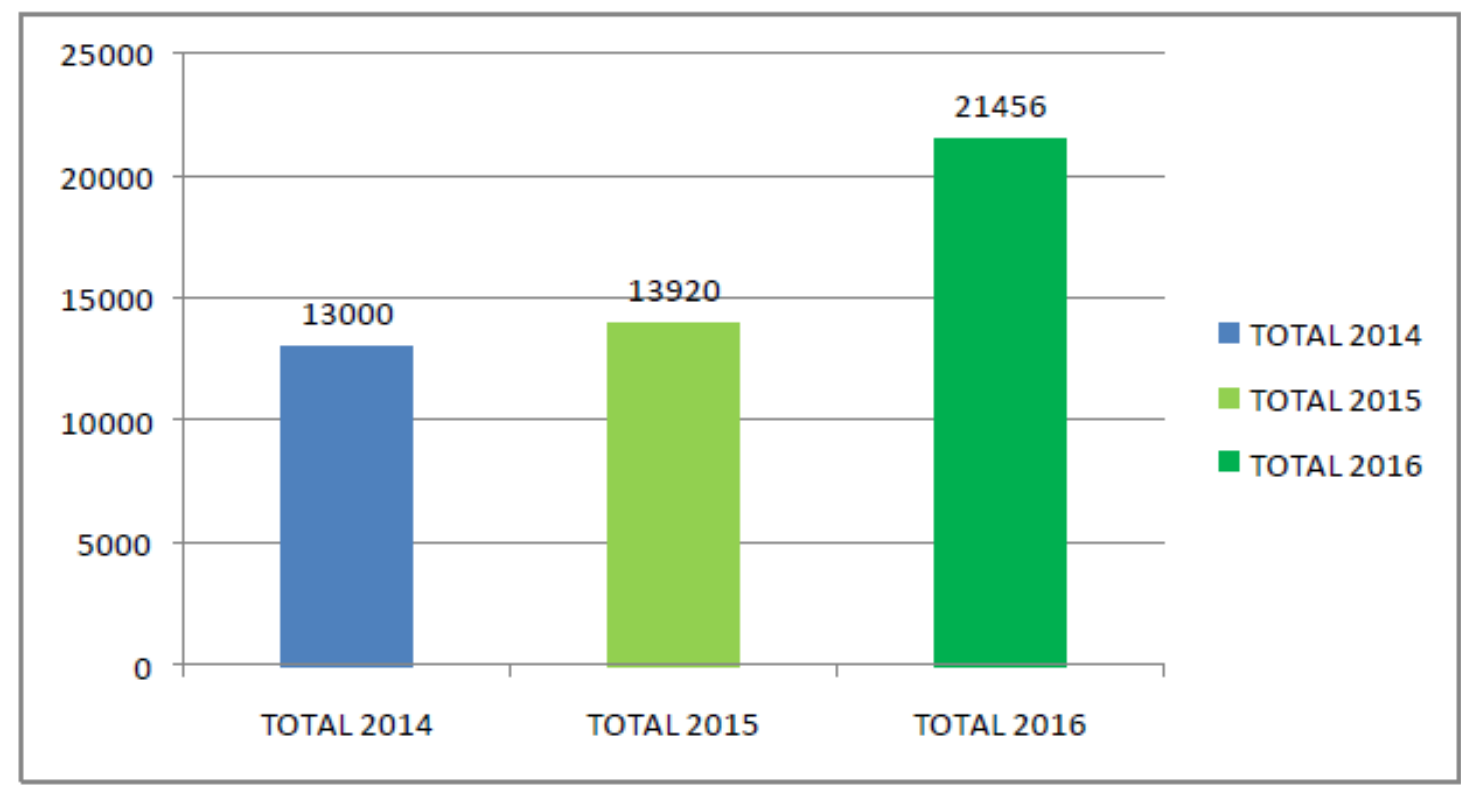

Figure 6. Bar chart showing all Malaria cases treated at health districts/facilities between January 2014 and

December 2016

\section{Discussion}

Malaria remains a major diseases burden to many developing countries (WHO, 2016). The finding of this study has not suggested anything different. The incidences of malaria diseases remain increasingly high. The knowledge and understanding of the pattern and distribution of Malaria disease are considered important to effective prevention and control management (Oxford, 2011).

This study finding showed the pattern and distribution of Malaria diseases have relatively maintained similar trend, at least over the past three years. The rise in incidence is noticed as from April, peaks between July and August and rescind as from September and October each year in the last three years. 
This to a large extent follows the pattern of rainfall and other environmental factors obtainable for the area. However, significant numbers of Malaria cases are still reported through other months of the year thus confirming the endemicity of Malaria disease among the population. According to Yusuf (2013), Malaria is influenced by a lot of environmental factors, which affects its seasonality, distribution, and transmission intensity. Lowe et al (2013) and Amek et al (2012) stated that climate is the significant contributing factor of the spatial and temporal distribution of malaria vectors and pathogens.

The major climatic factors influencing malaria transmission are rainfall, temperature and humidity (Reid et al 2012; Kalinga-Chirwa 2011). The finding of this study is thus in support of the previous study finding that rainfall pattern is a factor in determining the pattern of incidence of Malaria disease. Since the pattern and distribution have been consistent over the past few years, the implication for effective prevention and control is assumed to be positive, if other socio-economic, political and environmental factors are favourable. Prevention and control effort should well consider this finding when reviewing progress from past interventions, planning and implementing of future interventions.

The finding of this study which showed relatively higher proportion of incidents among under-five children with possible attendant consequences for mortality and disabilities is in support of other study finding. According to Walldor et al (2015), Under-5-year children are the most susceptible to malaria infections. Higher mortality was also reported among under 5 in other studies (WHO, 2015; Abdalla et al, 2007). The finding of this study, however, revealed that the proportion of under5 year Malaria cases to Total hospital under 5 consultation is much higher than revealed in previous studies from the same region (Walldor et al 2015; WHO 2013; Chanda et al, 2013). Why the proportion from this study was much higher among the under-five population should be of interest to the researcher, health managers and health policy makers.

While there has been a consistent pattern of reported cases in the first two years under review, it was noticed in the third year that the reported incidence of Malaria was much higher than the previous two years, although the trend in the pattern was maintained. The question that comes to mind is what could be responsible for these much higher reported cases of Malaria: could it be a case of outbreak, improved access to healthcare or reflection of population explosion with attendant morbidity burden? This presented another problem to be answered by researcher and health policy maker and managers.

From the pattern and distribution pattern as revealed by this study, a comprehensive and integrated approach from to prevention and control would be required government, health officials, partners and donors to move this area and most parts of South Sudan to a more acceptable level of Malaria epidemiologic status before its elimination (Oxford, 2011). The limitation of this study includes its inability to extensively disaggregate the data by sex.

\section{Conclusion and recommendation}

The finding of this study showed pattern and distribution of Malaria disease in the area over a period of three years maintained a similar trend. It did not suggest a reduction in the trend of incidence occurrence. The pattern and distribution have implication on prevention and control intervention approach. The finding provide some insights on the direction and context the prevention, treatment and eradication approach should follow in order to achieve better outcome. More attention should be given to under5 year population. Malaria control plans should significantly factor in the seasonal influence on the incidence. Generally the findings are important to better understanding and management of Malaria disease in Wulu County, many other counties in South Sudan and perhaps other malaria endemic region. Health managers and policy makers need to double their effort and give more attention to combating Malaria infections as it constitutes a big chunk of OPD Consultations and admissions.

We recommend further study into finding why the pattern might have not been halted over years despite the availability of proven and effective treatment regimen and preventive measures. Further study should be conducted to know the rationale behind the relatively lower proportion of reported Severe Malaria cases despite the high reported incidence to enhance status understanding and guide future 
interventions. It will also be of benefit to examine in future the impact of the population socio-economic status on burden of Malaria disease and its reduction strategy. The finding from these should be integrated into intervention plan to help achieve sustainable impact. Regular intervention impact assessment is important of great importance in order to ensure scarce resource been utilized is achieving the desired objectives.

\section{Acknowledgement}

The authors thank the county health department team for their support to this study as part of the capacity effort of the county health workforce. We thank Mrs Elizabeth A. Ayeni who proof read this manuscript.

\section{References}

[1]. Abdalla S.I., Malik E.M., and Ali K.M. (2007): The burden of malaria in Sudan: incidence, mortality and disability - adjusted life - years. Malar J, 6:97

[2]. Amek N, Bayoh N, Hamel M, Lindblade KA, Gimnig JE, Odhiambo F, et al (2012): Spatial and temporal dynamics of malaria transmission in rural Western Kenya. Parasit Vectors. 2012; 5:86. doi: 10.1186/1756-3305-586.

[3]. Chanda E., Doggale C., Pasquale H., Azairwe A., Baba S. and Mnzava A (2013): Addressing malaria vector control challenges in south Sudan: proposed recommendations. Malar J. 12:59

[4]. Kalinga-Chirwa R, Ngongondo C, Kalanda-Joshua M, Kazembe L, Pemba D, Kululanga E (2011): Linking rainfall and irrigation to clinically reported malaria cases in some villages in Chikhwawa District, Malawi. Phys Chem Earth Parts A/B/C. 2011; 36:887-894. doi: 10.1016/j.pce.2011.07.053.

[5]. Lowe R, Chirombo J, Tompkins AM (2013): Relative importance of climatic, geographic and socio-economic determinants of malaria in Malawi. Malar J. 2013; 12:416. doi: 10.1186/1475-2875-12-416.

[6]. Oxford (2011): Malaria endemicity. http://www.map.ox.ac.uk/explore/about-malaria/malaria-endemicity/

[7]. Reid HL, Haque U, Roy S, Islam N, Clements A (2012): Characterizing the spatial and temporal variation of malaria incidence in Bangladesh, 2007. Malar J. 2012; 11:170. doi: 10.1186/1475-2875-11-170.

[8]. RoSS (2009): Ministry of Health Malaria indicator survey report, Republic of south Sudan.

[9]. Tanner M., Greenwood B., Whitty C., Ansah E., Price R., Marsh K., Hemingway J., Osier F (2015): Malaria eradication and elimination: views on how to translate a vision into reality. Bio Medical Central, 13: 167

[10]. Yusuf SK. (2013): Spatial temporal impacts of climate variability on malaria distribution in Gulu and Mpigi districts in Uganda using GIS. MSc thesis, Asian Institute of Technology, Thailand, 2013. www.rsgis.ait.ac.th/rsweb2010/research/2013

[11]. Walldorf JA, Cohee LM, Coalson JE, Bauleni A, Nkanaunena K, Kapito-Tembo A, et al. (2015): School-age children are a reservoir of malaria infection in Malawi. PLoS ONE. 2015; 10(7):e0134061. doi: 10.1371/journal.pone.0134061.

[12]. WHO (2013): Country Cooperation strategy at a glance: belize. Geneva: World Health Organization; 2013.

[13]. WHO (2016): World Health Organization; Malaria. Intern. travel and health; visited 1st Oct, 2016. Available at http://www.who.int/ith/en/

[14]. WMR (2015): World Malaria Report 2015: Regional and Country profile. 